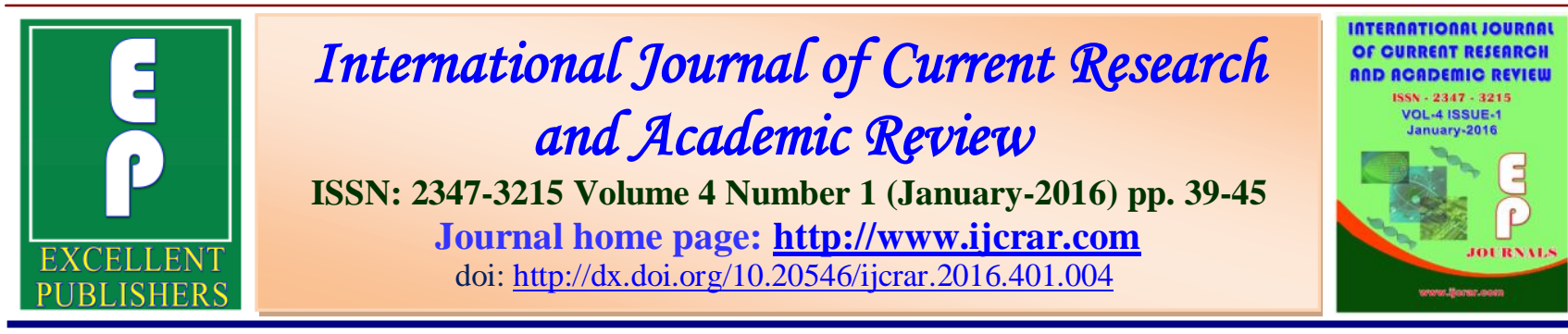

\title{
In Vitro Cultivation of Promastigotes of Iraqi Leishmanial Species in Serum-Free Liquid Medium Containing Human Urine
}

\author{
Husain F. Hassan*, Dunya S. Shakoor and Iman N. Mahmood \\ Department of Biology, College of Science, University of Kirkuk, Iraq \\ *Corresponding author
}

\begin{tabular}{|c|c|}
\hline KEYWORDS & A B S T R A C $T$ \\
\hline $\begin{array}{l}\text { Leishmania, } \\
\text { romastigote, } \\
\text { Serum free, } \\
\text { In vitro, } \\
\text { Culture }\end{array}$ & $\begin{array}{l}\text { A new serum free liquid culture medium containing sterile fresh human urine } \\
\text { was described for in vitro cultivation of Iraqi leishmanial promastigotes. The } \\
\text { medium is simple to prepare, easy to purchase and successful to obtain bulk } \\
\text { cultivation and maintenance of Leishmania donovani, L. tropica and } L \text {. major } \\
\text { promastigotes. }\end{array}$ \\
\hline
\end{tabular}

\section{Introduction}

A variety of culture media have been designed for cultivating the promastigote forms of different leishmanial species (Berens et al., 1976, McCarthy - Burke et al., 1991, Kar, 1997, Bagrova et al., 2012). There are three basic types of culture media: biphasic, semisolid and liquid. Biphasic and semisolid media need blood as one of their essential ingredients for isolation and maintenance of the parasites, whereas liquid media require foetal calf serum (FCS) or blood lysate for bulk cultivation and sustained cell multiplication (Berens and Marr, 1978, Steiger and Black, 1980, Ozbilgin et al., 1995, Limoncu et al., 1997, Somanna et al., 2002). Cell culture in blood or FCS supplemented media has certain disadvantages. Biphasic media is susceptible to bacterial contamination and fail to support the long term in vitro growth of promastigotes to obtain larger number for various studies (Visvesvara and Garcia, 2002). Foetal calf serum is highly expensive, difficult to transport and unavailable when needed specially in developing countries (Gupta and Saran, 1991; Merlen et al., 1999). In this communication we describe a cheap, an autoclavable serum free liquid medium and easy to purchase when needed in countries where leishmaniasis is endemic.

\section{Materials and Methods}

\section{Parasites and Growth Conditions}

Promastigote forms of Leishmania donovani (MHOM/IQ/81/BRC), L. tropica (MHOM IQ/93/MRC1) L. major, originally isolated from cutaneous leishmaniasis patients, were 
maintained routinely in modified Tobies biphasic (NNN) medium at $26^{\circ} \mathrm{C}$ as described (Chang and Hendricks, 1985). The composition of experimental media are given in Table 1. The $\mathrm{pH}$ of these media was adjusted to 7.4 with $1 \mathrm{~N} \mathrm{NaOH} / \mathrm{HCl}$. Medium 199, RPMI - 1640 and individual ingredients (i.e. folic acid, and adenosine) were filtered through $0.22 \mu \mathrm{m}$ Miller GV filters (Millipore). Medium HDI1, HDI2, HDI3 and HDI4 were generally sterilised by autoclaving at 15 psi for $15 \mathrm{~min}$. After the culture medium was either filter sterilised or autoclaved, $100 \mathrm{U} / \mathrm{ml}$ of penicillin and 0.1 $\mathrm{mg} / \mathrm{ml}$ streptomycin were added. Fresh urine was collected from a single adult male volunteer, cleared by centrifugation at 2000 $\mathrm{g}$ for $5 \mathrm{~min}$ and sterilised by passage through a $0.22 \mu \mathrm{m}$ membrane filter. FCS was heat inactivated at $55^{\circ} \mathrm{C}$ for $1 \mathrm{hr}$. Biphasic cultured promastigotes in late log growth were sedimented by centrifugation at $4000 \mathrm{~g}$ for $10 \mathrm{~min}$., washed twice with sterile Hanks' balanced salt solution (HBSS), and $0.5 \mathrm{ml}$ of the inoculum containing 106 parasites $/ \mathrm{ml}$ were introduced aseptically into $4.5 \mathrm{ml}$ of experimental culture medium. Cellular growth was estimated by counting the parasites in a Neubauer chamber. Cellular viability was assessed, before and after incubations, by motility as well as by light microscopy observation using Trypan blue cell dye exclusion for promastigote forms. The generation time $(\mathrm{G})$ of the parasite was determined as described by Kar (1997).

\section{Results and Discussion}

Typically promastigote forms of all species of Leishmania, when inoculated in to one of the experimental media to give initial concentrations of $105 \mathrm{cell} / \mathrm{ml}$, were able to grow to late log phase in about 5-6 days in the presence of $5 \%$ human urine.Long lag periods, approximately 24-48 hrs were observed in early transfere from biphasic
Tobies' medium to experimental media. These periods could reduced or eliminated by obtaining inocula from log phase populations. During the first transfere, it has been observed that the generation times were lower than previously reported values for Leishmania. The observed $\mathrm{G}$ values were $12.2,11.4$, and 11.8 in the early stationary growth phase, for $L$. donovani, L. tropica and L. major, respectively. By the second transfere, the generation time had increased to a relatively stable value depending on the medium and the leishmanial species used (Tables 2-4). It did not determine which components were responsible for the slightly better growth rate for Leishmania in experimental medium containing human urine, but it did seem to be due to supplementation with brain heart infusion( $\mathrm{BHI}$ ) and peptone or BHI and folic acid. Significant stimulation of growth was found with $100 \mathrm{mg} / \mathrm{liter}$ (w/v) folic acid. Maximum numbers of parasite of approximately $\left(1.9 \times 107 \_3.8 \times 107\right.$ cells $\left./ \mathrm{ml}\right)$ were found in the early stationary phase after 6-7 days. Growth was observed also after 10 days incubation at $26^{\circ} \mathrm{C}$. Reproduction of parasites in experimental medium and original Tobies' medium is shown in Tables 2-4. The morphology of cells grown in experimental medium were all demonstrated the typical elongate, flagellated promastigote morphology (Figure 1).

Several reports have indicated the requirement of inorganic salts, glucose and amino acids for the propagation of the leishmanial promastigotes (Steiger and Steiger, 1997, Chaudhuri et al., 1986, Beltran et al., 1988). In addition, purine as well as many vitamins and related growth factors including folic acid and hemin are essential for Leishmania (Steiger and Meshnick, 1977, Merino and Gabaldon, 1978, Melo et al., 1985, Lemesre et al., 1988). 
Int.J.Curr.Res.Aca.Rev.2016; 4(1): 39-45

Table.1 Composition of the Expermental Media

\begin{tabular}{|c|c|c|c|c|c|c|c|}
\hline Component & HDI 1 & HDI 2 & HDI 3 & HDI 4 & M199 & RPMI 1640 & NNN \\
\hline $\mathrm{NaCl}$ & 0.8 & 0.8 & 0.8 & 0.8 & 0.8 & 0.8 & $0.8^{+}$ \\
\hline $\mathrm{KCl}$ & 0.04 & 0.04 & 0.04 & 0.04 & 0.04 & 0.04 & $0.04^{+}$ \\
\hline $\mathrm{CaCl}_{2}$ & 0.014 & 0.014 & 0.014 & 0.014 & 0.014 & 0.014 & $0.16^{+}$ \\
\hline $\mathrm{MgCl}_{2} \cdot 6 \mathrm{H}_{2} \mathrm{O}$ & 0.02 & 0.02 & 0.02 & 0.02 & 0.02 & 0.02 & \\
\hline $\mathrm{Na}_{2} \mathrm{HPO}_{4}$ & 0.015 & 0.015 & 0.015 & 0.015 & 0.015 & 0.015 & \\
\hline $\mathrm{KH}_{2} \mathrm{PO}_{4}$ & 0.006 & 0.006 & 0.006 & 0.006 & 0.006 & 0.006 & \\
\hline $\mathrm{NaHCO}_{3}$ & 0.035 & 0.035 & 0.035 & 0.035 & 0.035 & 0.035 & $0.02^{+}$ \\
\hline Glucose & 0.1 & 0.1 & 0.1 & 0.1 & 0.1 & 0.1 & $0.2^{+}$ \\
\hline Yeast extract* & 0.25 & & & & & & \\
\hline Beef extract ${ }^{\star *}$ & 0.35 & 0.35 & 0.35 & 0.35 & & & $0.04^{++}$ \\
\hline Bacto Peptone ${ }^{\star \star}$ & 1.0 & & & 1.0 & & & $0.052^{++}$ \\
\hline $\mathrm{BHI}^{*}$ & & 3.7 & 3.7 & 3.7 & & & \\
\hline Folic acid & & 0.001 & & & 0.004 & 0.004 & \\
\hline Glutamine & & & 0.1 & & & & \\
\hline M199 & & & & & 1.0 & & \\
\hline MEM Eagle & & & & & 0.18 & 0.18 & \\
\hline RPMI 1640 & & & & & & 1.3 & \\
\hline Agar & & & & & & & $2.0^{++}$ \\
\hline Adenosine & & & & & 0.005 & 0.005 & \\
\hline
\end{tabular}

* Oxoid London, United Kingdom.

** Gibco/BRL, Gaithersburg, MD.

+ Liquid phase of NNN medium.

++ Solid phase of NNN medium, in addition defibrinated, heat inactivated and hemolysed (with equal volume of distilled water) rabbit blood was used.

Table.2 Cultivation of L. donovani Promastigotes in Different Media

\begin{tabular}{|c|c|c|c|c|c|}
\hline \multirow{2}{*}{ Medium } & \multicolumn{5}{|c|}{ No. of promastigotes* on day } \\
\hline & 2 & 4 & 6 & 8 & $\mathrm{G}^{* *}$ \\
\hline HDI 1 & $3.8 \times 10^{6}$ & $1.8 \times 10^{7}$ & $2.7 \times 10^{7}$ & $2.9 \times 10^{7}$ & 17.606 \\
\hline HDI 2 & $5 \times 10^{6}$ & $3.1 \times 10^{7}$ & $3.8 \times 10^{7}$ & $4.0 \times 10^{7}$ & 16.658 \\
\hline HDI 3 & $2.9 \times 10^{6}$ & $1.4 \times 10^{7}$ & $2.2 \times 10^{7}$ & $2.4 \times 10^{7}$ & 18.214 \\
\hline HDI 4 & $3.3 \times 10^{6}$ & $2.1 \times 10^{7}$ & $3.2 \times 10^{7}$ & $3.4 \times 10^{7}$ & 17.126 \\
\hline M199 & $4.5 \times 10^{6}$ & $3.6 \times 10^{7}$ & $9 \times 10^{7}$ & $9.8 \times 10^{7}$ & 14.67 \\
\hline RPMI 1640 & $5 \times 10^{6}$ & $5.5 \times 10^{7}$ & $6.4 \times 10^{7}$ & $6.8 \times 10^{7}$ & 15.44 \\
\hline $\mathrm{NNN}$ & $9.6 \times 10^{5}$ & $7 \times 10^{6}$ & $8.1 \times 10^{6}$ & $9.6 \times 10^{6}$ & 22.7 \\
\hline
\end{tabular}

*Initial inoculation, 105 promastigotes.

**Generation time on day 6 .

M199 and RPMI 1640 medium were supplemented with 10\% heat inactivated foetal calf Serum. 
Int.J.Curr.Res.Aca.Rev.2016; 4(1): 39-45

Table.3 Cultivation of L. major Promastigotes in Different Media

\begin{tabular}{|c|c|c|c|c|c|}
\hline \multirow{2}{*}{ Medium } & \multicolumn{5}{|c|}{ No. of promastigotes* on day } \\
\hline & 2 & 4 & 6 & 8 & $\mathrm{G}^{* *}$ \\
\hline HDI 1 & $5.6 \times 10^{5}$ & $5 \times 10^{6}$ & $1.08 \times 10^{7}$ & $1.1 \times 10^{7}$ & 19.737 \\
\hline HDI 2 & $2 \times 10^{6}$ & $1.1 \times 10^{7}$ & $1.9 \times 10^{7}$ & $2 \times 10^{7}$ & 19.027 \\
\hline HDI 3 & $1.6 \times 10^{6}$ & $8 \times 10^{6}$ & $1.15 \times 10^{7}$ & $1.2 \times 10^{7}$ & 21.043 \\
\hline HDI 4 & $1.25 \times 10^{6}$ & $1.05 \times 10^{7}$ & $1.35 \times 10^{7}$ & $1.4 \times 10^{7}$ & 20.350 \\
\hline M199 & $4 \times 10^{6}$ & $3 \times 10^{7}$ & $8 \times 10^{7}$ & $7.4 \times 10^{7}$ & 14.93 \\
\hline RPMI 1640 & $3.4 \times 10^{6}$ & $3.8 \times 10^{7}$ & $5.6 \times 10^{7}$ & $5.8 \times 10^{7}$ & 15.77 \\
\hline $\mathrm{NNN}$ & $1.1 \times 10^{6}$ & $6.4 \times 10^{6}$ & $7.3 \times 10^{6}$ & $8.4 \times 10^{6}$ & 23.26 \\
\hline
\end{tabular}

*Initial inoculation, 105 promastigotes.

** Generation time on day 6.

M199 and RPMI 1640 medium were supplemented with $10 \%$ heat inactivated foetal calf Serum.

Table.4 Cultivation of L. tropica Promastigotes in Different Media

\begin{tabular}{|l|c|c|c|c|l|}
\hline \multirow{2}{*}{ Medium } & \multicolumn{5}{|c|}{ No. of promastigotes* on day } \\
\cline { 2 - 6 } & 2 & 4 & \multicolumn{2}{|c|}{6} & \multicolumn{2}{c|}{8} & \multicolumn{2}{|c|}{ G** $^{* *}$} \\
\hline HDI 1 & $3.5 \times 10^{6}$ & $1.7 \times 10^{7}$ & $2.26 \times 10^{7}$ & $2.4 \times 10^{7}$ & 18.414 \\
\hline HDI 2 & $3 \times 10^{6}$ & $1.7 \times 10^{7}$ & $2.4 \times 10^{7}$ & $2.6 \times 10^{7}$ & 18.214 \\
\hline HDI 3 & $4 \times 10^{6}$ & $1.4 \times 10^{7}$ & $2.1 \times 10^{7}$ & $2.1 \times 10^{7}$ & 18.667 \\
\hline HDI 4 & $2.5 \times 10^{6}$ & $2 \times 10^{7}$ & $2.3 \times 10^{7}$ & $2.3 \times 10^{7}$ & 18.360 \\
\hline M199 & $3.4 \times 10^{6}$ & $2.7 \times 10^{7}$ & $6 \times 10^{7}$ & $6.4 \times 10^{7}$ & 15.6 \\
\hline RPMI 1640 & $4.2 \times 10^{6}$ & $4.6 \times 10^{7}$ & $5.6 \times 10^{7}$ & $6 \times 10^{7}$ & 15.77 \\
\hline NNN & $1 \times 10^{6}$ & $6 \times 10^{6}$ & $7.8 \times 10^{6}$ & $8 \times 10^{6}$ & 22.91 \\
\hline
\end{tabular}

*Initial inoculation, 105 promastigotes.

** Generation time on day 6.

M199 and RPMI 1640 medium were supplemented with $10 \%$ heat inactivated foetal calf

Serum. 
Figure.1 Growth of Promastigotes of L. tropica (400x) (a) L. Major (400x) (b) and L. donovani (1000x) (c) in HDI 4 Media Supplemented with 5\% Human Urine
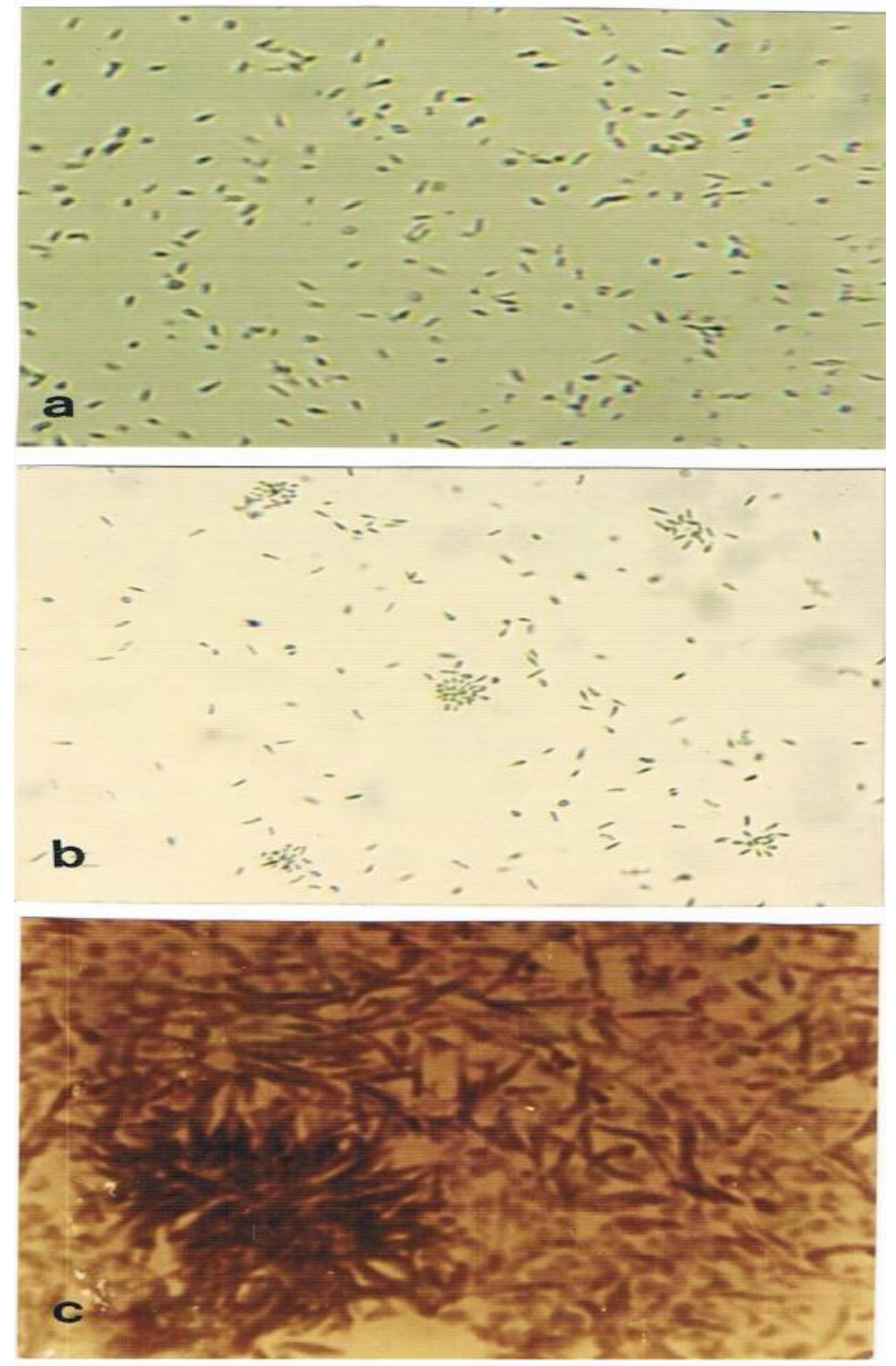

Several defined and semidefined liquid medium have been used for maintenance of leishmanias at $26^{\circ} \mathrm{C}$ and FCS favors the cultivation of promastigotes, as itis considered to be essential source for heme, which Leishmania unable to synthesize (Chang and Chang, 1985, Gupta and Saran, 1991).Fetal calf serum could be substituted by human urine to sustain the multiplication of many leishmanial promastigotes (Evans, 1986, Howard et al.,1991, Armstrong and
Patterson, 1994) infering that the urine offers the advantage of being not only as mere source of a complex various reagents but also as free, easily available when needed anywhere. In the present study, we describe the feasibility of culturing three leishmanial promastigotes through serially propagated in HDI1, HDI2, HDI3 and HDI4 urine supplemented medium. Supplementation of beef extract and brain heart infusion(BHI), was found beneficial 
for not only routine serial subpassages but also for providing large numbers of cells. However $L$. donovani shows a more rapid growth and a higher final density $(3.8 \times 107$ cell/ml; G 16.65) than L. tropica $(2.4 \times 107$ cells/ml; G 18.21) and L. major $(1.9 \times 107$ cells/ml; G 19.02). Beef extract and BHI serves as major source for heme and amino acids repectively, which are essential for the survival of the parasite (Kar, 1997, Ali et al., 1998). It is also noted that the supplementation of peptone, a source of amino acids, supported the propagation of the promastigotes. Glutamine in the course of this investigation, seems to be not essential for growth of promastigotes probably may be synthesized de novo by the parasite. The supplementation of proline was found to be prominent in the sustaining the multiplication of the parasite due to its use as a source of energy (Krassner and Flory, 1972). To compare our medium with other defined or semidefined media (Medium 199 and RPMI-1640) used for the cultivation of pathogenic hemoflagellate, we found that the culture inoculated at 105 cells $/ \mathrm{ml}$ can last 6-7 days to reach log phase, whereas, in medium 199 and RPMI-1640 the parasite reach the log phase within 3-4 days postinoculation. Our medium are considerably simple to prepare, easy to purchase and may therefore be the mixture of choice in the future for studies dealing with the cell biology, biochemistry, nutrition, immunology and chemotherapy of pathogenic species of Leishmania.

\section{References}

Ali S, Iqbal J, Ahmad B, Masoom M.1998. A semisynthetic fetal calf serum free liquid medium for in vitro cultivation of Leishmania promastigotes. Am J Trop Med Hyg 59: 163-165.

Armstrong T,Patterson L.1994. Cultivation of Leishmania braziliensis in an economical serum free medium containing human urine. J Parasitol 80: 1030-1032.

Bagrova M, Koc R, Allahverdiyer A, Ersoz A.2012. Effect of cell conditioned media on biomass production of Leishmania parasite. Turkish J Biol 36: 653-657.

Beltran S, Tesh R, Carvajal D, Arjona A.1988. An in vitro method for long term maintenance of Leishmania donovani chagasi. Trans Roy Soc Trop Med Hyg 82: 234-235.

Berens R, Birun R, Krassner S.1976. Axining cultivation of amastigote of Leishmania donovani and L. maior and their infectivity. Am Trop Med Parasitol 86: 487-502.

Berens R, Marr J.1978. An easily prepared defined medium for cultivation of Leishmania donovani promastigotes. J Parasitol 46: 160.

Chang C, Chang K.1985. Heme requirement and acquisition by extracellular stages of Leishmania mexicana amazonensis. Mol Biochem Parasitol 16: 267-276.

Chang K, Hendricks L.1985. Laboratory cultivation and maintenance of Leishmania. In: Chang K, Bray R, eds. Leishmaniasis, Elsevier Sci Pub, New York.

Chandhuri K, Sen S, Banerjee A.1986. A new medium for large scale production of Leishmania donovani promastigotes for biochemical studies. Indian $\mathrm{J}$ Med Res 84: 457-460.

Evans D.1986. An inexpensive easily available replacement of fetal calf serum in media for the in vitro cultivation of Leishmania spp. Z Parasit 72: 567-572.

Gupta A, Saran R.1991. In vitro maintenance of Leishmania donovani promastigotes in a cheap, serum free, hemin based autoclavable culture medium. J Comm Dis 23: 276-277. 
Howard M, Pharoah M, Ashal F, Miles M.1991.Human urine stimulates growth of Leishmania in vitro. Trans Roy Soc Trop Med Hyg 85: 477-479.

Kar K.1997. Folic acid the essential supplement to brain heart infusion both for cultivation and cloning of Leishmania donovani promastigotes. Parasit 115: 231-235.

Krassner S, Flory B.1972. Proline metabolism in Leishmania donovani promastigotes. J Protozool 19: 682-685.

Lemesre J, Darcy F, Kweider M, Capron A, Santoro, P.1988. Requirements of defined cultivation conditions for standard growth of Leishmania promastigotes in vitro. Acta Trop 45: 99-108.

Limoncu M, Balcioglu J, Yereli K, Ozbel Y, Ozbelgin A.1997. A new experimental in vitro culture medium for cultivation of Leishmania species. J Clin Microbial 35: 2430-2431.

McCarthy- Burke C, Bates P, Dwyer D.1991. Leishmania donovani: use of two different commercially available chemically defined media for the continuous in vitro cultivation of promastigotes. Exp Parasit 73: 385-387.

Melo N, Azevedo H, Roitman I, Mayrink W.1985. A new defined medium for cultivating Leishmania promastigotes. Acta Trop 42: 137-141.
Merino F, Gabaldon I.1978. In vitro culture of Leishmania braziliensis in a semidefined medium. Acta Cient Venez 29: 181-182.

Merlen T, Sereno D, Brajon N.1999. Leishmania species: completely defined media without serum and macromolecules for the continuous cultivation of infective promastigote forms. Am J Trop Med Hyg 60: 41-50.

Ozbilgin A, Ozbel Y, Alkan M, Atambay M, Ozcel M.1995. Cultivation of Leishmania sp. In nutrient broth. J Egypt Soc Parasit 25: 437-441.

Somanna A, Mundodi V, Gedamu L.2002. In vitro cultivation and characterization of Leishmania chagasi amastigote like forms. Acta Trop 83: 37-42.

Steiger R, Black C.1980. Simplified media for cultivating Leishmania donovani promastigotes. Acta Trop 37: 446-449.

Steiger R, Meshnick S.1977. Amino acid and glucose utilisation of Leishmania donovani and L. braziliensis. Trans Roy Soc Trop Med Hyg 71: 441-443.

Steiger R, Steiger E.1977. Cultivation of Leishmania donovani and $L$. braziliensis in defined media, nutritional requirements. J Protozool 24: 437-441.

Visvesvara G, Garcia L.2002. Culture of protozoan parasites. Clin Microb Rev 15: 323-328.

\section{How to cite this article:}

Husain F. Hassan, Dunya S. Shakoor and Iman N. Mahmood. 2016. In Vitro Cultivation of Promastigotes of Iraqi Leishmanial Species in Serum-Free Liquid Medium Containing Human Urine. Int.J.Curr.Res.Aca.Rev. 4(1): 39-45 doi: http://dx.doi.org/10.20546/ijcrar.2016.401.004 